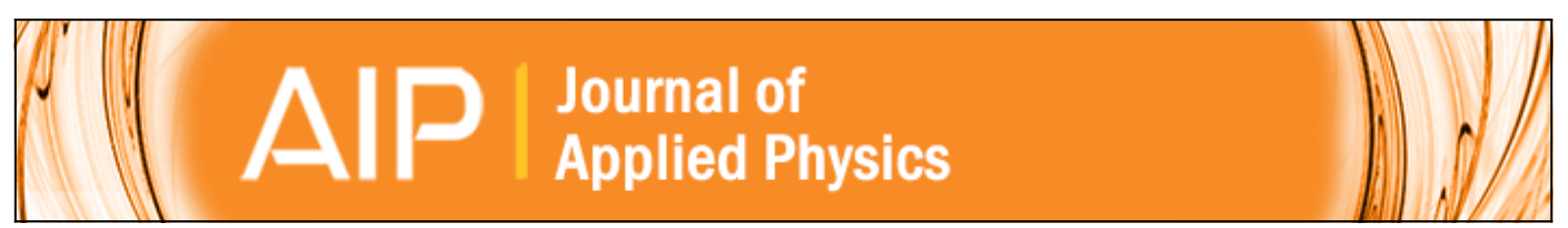

Effect of hydrofluoric acid concentration on the evolution of photoluminescence characteristics in porous silicon nanowires prepared by Ag-assisted electroless etching method

A. Najar, A. B. Slimane, M. N. Hedhili, D. Anjum, R. Sougrat, T. K. Ng, and B. S. Ooi

Citation: Journal of Applied Physics 112, 033502 (2012); doi: 10.1063/1.4740051

View online: http://dx.doi.org/10.1063/1.4740051

View Table of Contents: http://scitation.aip.org/content/aip/journal/jap/112/3?ver=pdfcov

Published by the AIP Publishing

AlP 


\title{
Effect of hydrofluoric acid concentration on the evolution of photoluminescence characteristics in porous silicon nanowires prepared by Ag-assisted electroless etching method
}

\author{
A. Najar, ${ }^{1}$ A. B. Slimane,${ }^{1}$ M. N. Hedhili, ${ }^{2}$ D. Anjum, ${ }^{2}$ R. Sougrat,${ }^{2}$ T. K. Ng, ${ }^{1}$ \\ and B. S. Ooi ${ }^{1, a)}$ \\ ${ }^{1}$ Photonics Laboratory, King Abdullah University of Science and Technology (KAUST), Thuwal, \\ Kingdom of Saudi Arabia \\ ${ }^{2}$ Advanced Nanofabrication, Imaging and Characterization Core Laboratory, King Abdullah University \\ of Science and Technology (KAUST), Thuwal, Kingdom of Saudi Arabia
}

(Received 3 February 2012; accepted 2 July 2012; published online 1 August 2012)

\begin{abstract}
We report on the structural and optical properties of porous silicon nanowires (PSiNWs) fabricated using silver $(\mathrm{Ag})$ ions assisted electroless etching method. Silicon nanocrystallites with sizes $<5 \mathrm{~nm}$ embedded in amorphous silica have been observed from PSiNW samples etched using the optimum hydrofluoric acid (HF) concentration. The strongest photoluminescence (PL) signal has been measured from samples etched with $4.8 \mathrm{M}$ of $\mathrm{HF}$, beyond which a significant decreasing in PL emission intensity has been observed. A qualitative model is proposed for the formation of PSiNWs in the presence of $\mathrm{Ag}$ catalyst. This model affirms our observations in PL enhancement for samples etched using $\mathrm{HF}<4.8 \mathrm{M}$ and the eventual PL reduction for samples etched beyond 4.8 M of HF concentration. The enhancement in PL signals has been associated to the formation of PSiNWs and the quantum confinement effect in the Si nanocrystallites. Compared to PSiNWs without $\mathrm{Si}-\mathrm{O}_{\mathrm{x}}$, the HF treated samples exhibited significant blue PL peak shift of $100 \mathrm{~nm}$. This effect has been correlated to the formation of defect states in the surface oxide. PSiNWs fabricated using the electroless etching method can find useful applications in optical sensors and as anti-reflection layer in silicon-based solar cells. (c) 2012 American Institute of Physics. [http://dx.doi.org/10.1063/1.4740051]
\end{abstract}

\section{INTRODUCTION}

Nanoscale silicon has been intensively investigated and explored for its applications in microelectronics, photonics, and biomedical sensors. ${ }^{1-3}$ Specific efforts have been concentrated in the development of new silicon nanostructures, including quantum dots, nanowires, or porous silicon (PS). Porous silicon has attracted much attention, especially in enhancing photo-emission. Much research efforts have been invested to realize an optical device with porous silicon, ${ }^{4-6}$ but the inefficiency ${ }^{7}$ and instability ${ }^{8}$ of optical characteristic in PS still remain. In addition, silicon nanowires (SiNWs) are also ideal candidate for the study of physics of lowdimensional systems. It has potential impact in realizing nanoscale interconnects and functional device elements in future nanoscale electronic and optoelectronic devices. ${ }^{9,10}$

The field of SiNWs synthesis represents an exciting and rapidly expanding research area. Considerable efforts have been devoted to the development of versatile and controllable methods for the synthesis of SiNW. These methods can be broadly classified as: (i) bottom-up, and (ii) top-down approaches. The bottom-up approach involves the construction of desirable nanostructures from the basic components, i.e., from the atomic level to the nano- or micro-scale wires. This method is useful for the fabrication of low-dimensional

\footnotetext{
a) Author to whom correspondence should be addressed. Electronic mail: boon.ooi@kaust.edu.sa.
}

heterostructure based devices in large quantities. ${ }^{11,12}$ Using bottom-up, SiNWs were first obtained by vapor-liquid-solid (VLS) method, ${ }^{13}$ followed by an etching step to create nanowires. The VLS method has been implemented in a variety of techniques, such as pulsed laser deposition (PLD), ${ }^{14,15}$ gas-phase molecular beam epitaxy (GS-MBE) ${ }^{16}$ chemical vapor deposition (CVD),${ }^{17,18}$ laser ablation, ${ }^{19,20}$ and oxideassisted growth techniques. ${ }^{21}$

Top-down approach seeks to fabricate SiNWs from high quality single crystal silicon wafer or thin film. Silicon nanowires have also been realized using lithographically defined patterns, or spin-coating of nanospheres as etched mask, ${ }^{22}$ followed by etching of the nanowires using plasma processing technique. The fabrication of silicon nanowires using the metal-assisted electroless etching method has also been adopted. ${ }^{23-25}$ The silver $(\mathrm{Ag})$ ions in an ionic solution of hydrofluoric acid (HF) and hydrogen peroxide $\left(\mathrm{H}_{2} \mathrm{O}_{2}\right)$ have been used to prepare the arrays of SiNWs from single crystal wafers. ${ }^{26,27}$ The effects of various process parameters such as the etchant concentration of $\mathrm{H}_{2} \mathrm{O}_{2}$, etching time and postetch treatment on the morphology and optical properties of the SiNWs have also been investigated. ${ }^{28}$ The fabrication of nanowires using this method does not require complex sample preparation steps. Furthermore, this technique is effective, having high throughput and low cost.

In this paper, we explore the effect of HF concentration on the formation of porous silicon nanowires (PSiNWs) with the aim of establishing a better understanding of the 
formation mechanisms of mesopores and nanocrystalline structures in the PSiNWs. A qualitative model based on the SEM observations with inferences from PL, high resolution TEM, and XPS will be developed.

\section{EXPERIMENTS}

PSiNWs were fabricated by Ag assisted electroless etching method from a n-type $\mathrm{Si}$ wafer (100) with a resistivity of $0.01-0.02 \Omega \mathrm{cm}$. The Si wafers were cleaned using acetone followed by ethanol for $5 \mathrm{~min}$ in an ultrasonic bath. Next, the wafers were immersed in a piranha solution $\mathrm{H}_{2} \mathrm{SO}_{4} /$ $\mathrm{H}_{2} \mathrm{O}_{2}=(3: 1)$ for 20 min to remove the organic deposits from the surface. The cleaned wafers were transferred into $\mathrm{HF} /$ $\mathrm{AgNO}_{3}$ solution with a concentration of $4.8 \mathrm{M} / 0.005 \mathrm{M}$ for $\mathrm{Ag}$-deposition, followed by rinsing with de-ionized water. Then, the treated Si samples were etched in the $\mathrm{HF} / \mathrm{H}_{2} \mathrm{O}_{2}$ solution for $45 \mathrm{~min}$. Finally, samples were rinsed again for 10 min with $\mathrm{HNO}_{3}$ solution to dissolve the excessive $\mathrm{Ag}$ nanoparticles (Ag NPs), leaving behind traces of Ag for catalyzing the etching reaction. Four samples were etched using $\mathrm{HF}$ concentration of $1.8,2.8,4.8$, and $5.8 \mathrm{M}$, respectively, with a fixed $\mathrm{H}_{2} \mathrm{O}_{2}$ concentration of $0.5 \mathrm{M}$.

The surface morphology of PSiNWs was investigated using a FEI's Magellan 400 FEG SEM operating at $5 \mathrm{keV}$ beam energy. The crystal structure, size of Si crystallites, and the average pore size were measured using the FEI's $\operatorname{TitanG}^{2}$ 80-300 TEM. X-ray energy-dispersive spectroscopy (EDS) analysis of PSiNWs was carried out with an X-ray detector from EDAX (EDAX, Mahwah, NJ) attached to the TEM. Energy filtered TEM (EFTEM) was also performed to separate the crystalline phase of $\mathrm{Si}$ from its amorphous oxide phase using a GIF Tridiem ${ }^{\mathrm{TM}}$ post-column energy filter from Gatan. The photoluminescence (PL) measurements were performed at room temperature using the Jobin Yvon LabRAM ARAMIS system. A $8 \mathrm{~mW}$ diode-pumped solid-state (DPSS) laser emitting at $473 \mathrm{~nm}$ was used as the PL excitation source. The XPS studies were carried out in a Kratos Axis Ultra DLD spectrometer equipped with a monochromatic Al $K \alpha$ x-ray source $(h \nu=1486.6 \mathrm{eV} h \nu)$ in $1 \times 10^{-9}$ Torr vacuum. The spectrometer dispersion was adjusted to give a binding energy of $932.63 \mathrm{eV}$ for metallic $\mathrm{Cu}^{2} \mathrm{p}_{3 / 2}$. Samples were mounted in floating mode in order to avoid differential charging. ${ }^{29,30}$ Charge neutralization was required for all samples. Binding energies were referenced to the $\mathrm{C} 1 \mathrm{~s}$ binding energy of adventitious carbon contamination which was taken to be $284.80 \mathrm{eV}$. The measured data were analyzed by fitting the individual peaks with a Gaussian (70\%)-Lorentzian $(30 \%)$ function.

\section{RESULTS AND DISCUSSIONS}

In the presence of $\mathrm{Ag}$ catalyst, an increase in $\mathrm{HF}$ or $\mathrm{H}_{2} \mathrm{O}_{2}$ concentration in electroless etching method is analogous to an increase in the current density in electrochemicalbased methods. ${ }^{31,32}$ In both cases, increasing the $\mathrm{H}_{2} \mathrm{O}_{2}$ or $\mathrm{HF}$ concentration increases the oxidation rate and dissolution rate, respectively, resulting in nanostructures with varying optical properties. ${ }^{33}$ Figures $1(\mathrm{a})$ to $1(\mathrm{~h})$ show the crosssection SEM micrographs and TEM images acquired from
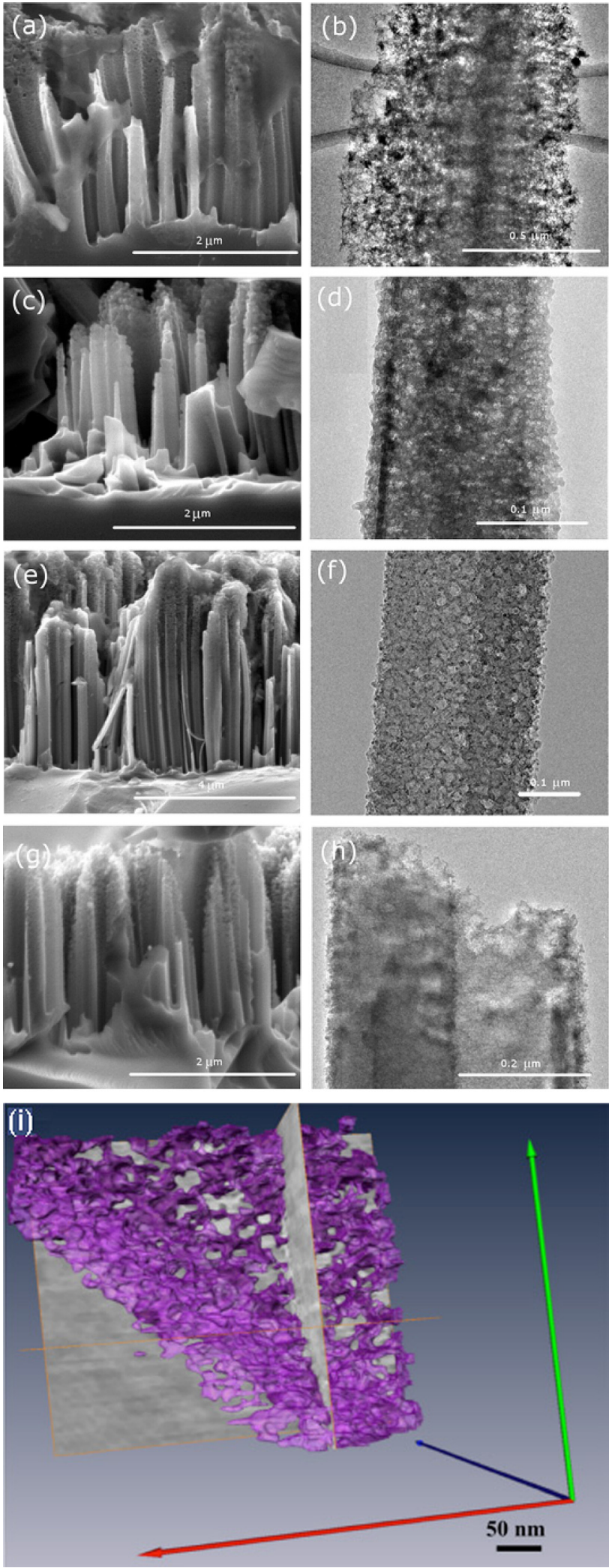

FIG. 1. (a)-(h) SEM and TEM micrographs of PSiNWs fabricated with increasing $\mathrm{HF}$ concentration from 1.8, 2.8, 4.8, up to $5.8 \mathrm{M}$. (i) 3D tomography TEM image of nanowires in (f).

the NW samples grown with $\mathrm{HF}$ concentration of $1.8 \mathrm{M}$, $2.8 \mathrm{M}, 4.8 \mathrm{M}$, and $5.8 \mathrm{M}$ in a fixed $\mathrm{H}_{2} \mathrm{O}_{2}$ concentration of 0.5 M. From Fig. 1(i), a typical 3D-tomography observation was conducted using a TEM and 3D reconstructions were 
TABLE I. Effect of HF concentration on PSiNWs length, NWs diameter, and aspect ratio analyzed from SEM micrographs.

\begin{tabular}{lcccc}
\hline \hline & \multicolumn{4}{c}{ HF concentration } \\
\cline { 2 - 5 } PSiNWs physical parameters & $1.8 \mathrm{M}$ & $2.8 \mathrm{M}$ & $4.8 \mathrm{M}$ & $5.8 \mathrm{M}$ \\
\hline NWs length $(\mu \mathrm{m})$ & $1.3-1.8$ & $2-2.2$ & $4.8-5.3$ & $1.6-1.8$ \\
NWs diameter $(\mathrm{nm})$ & $160-210$ & $100-180$ & $80-200$ & $150-200$ \\
$\begin{array}{l}\text { Aspect ratio } \\
\text { (longest length/largest diameter) }\end{array}$ & $\sim 9$ & $\sim 12$ & $\sim 27$ & $\sim 9$ \\
\hline \hline
\end{tabular}

achieved using a simultaneous iterative reconstruction algorithm of consecutive 2D slices in Fig. 1(f). The pore sizes present a distribution from 10 to $50 \mathrm{~nm}$, with an estimated measurement error of $10 \%$, and these pores go inside the nanowire showing similar structure to porous silicon. An average distance between two neighboring pores of lower than $5 \mathrm{~nm}$ has been observed. These mesoporous structures are expected to show strong quantum confinement effects. The variation of NWs length, and NWs diameter with increasing HF concentrations were measured and analyzed using SEM and TEM, and the results are tabulated in Table I. The NWS length shows significant changes, while the NWs diameter varies from $80 \mathrm{~nm}$ to $210 \mathrm{~nm}$ for samples indicating the dominant effect of vertical etching enhanced by Ag catalyst with preferential etching along the low atomic density plane in
[001]. An increase in aspect ratio from about 9 to 12 and 27 has been calculated for NWs samples etched with $1.8 \mathrm{M}$, 2.8 M, and 4.8 M HF concentration (Figs. 1(a), 1(c), and 1(e)). However, the aspect ratio reduces to about 9 for NWs etched with (Fig. 1(g)) signifying a change in etching mechanism with faster lateral chemical etch.

To identify the causes of the transition point between the vertical-dominant to lateral-dominant etching in the chemical process, the pore-density of the nanowires have been examined thoroughly. The TEM images show clearly that samples prepared with $4.8 \mathrm{M}$ of $\mathrm{HF}$ concentration present relatively high pore density compared to samples prepared with $5.8 \mathrm{M}$ of $\mathrm{HF}$. The monotonic increase in the pore-density evidently showed that lateral oxidation process at a fixed $\mathrm{H}_{2} \mathrm{O}_{2}$ concentration dominates at low $\mathrm{HF}$ concentration of $\leq 4.8 \mathrm{M}$ due to a limited $\mathrm{HF}$ dissolution rate. As $\mathrm{HF}$ concentration increases, the HF dissolution rate increases to the extent that the PSiNWs apexes were effectively dissolved at the highest $\mathrm{HF}$ concentration of $5.8 \mathrm{M}$, forming conical PSiNWs. Hence, the reaction (dissolution) rate dominates the lateral PSiNWs chemical etching process at high HF concentration, while the diffusion of HF etching species and byproducts dominates at low HF concentration. In the following paragraphs, we further explain the role of $\mathrm{Ag}$ nanopartiules and ionic $\mathrm{Ag}^{+}$in the formation of conical PSiNWs, the transport of etchant and other by products in the nanowires.

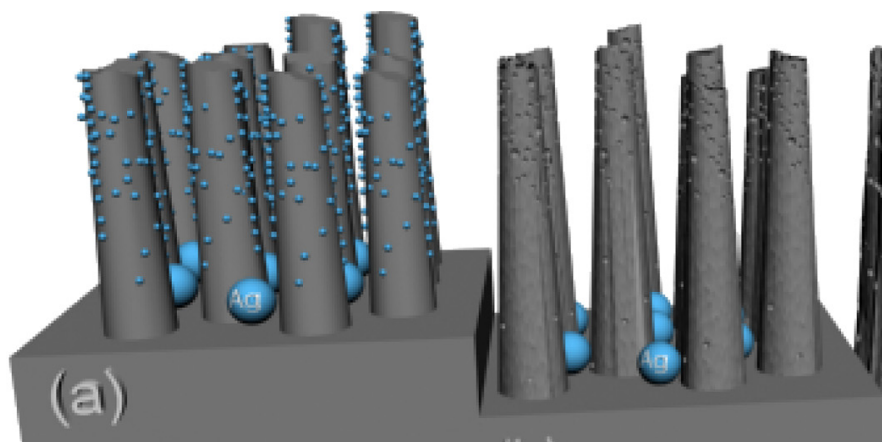

Substrate

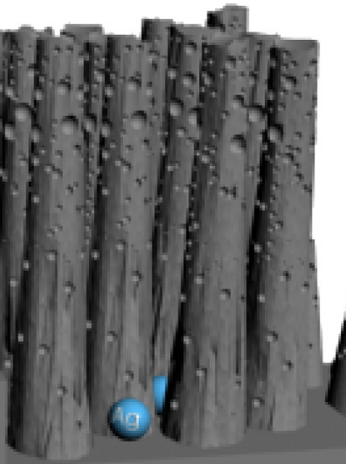

(c)

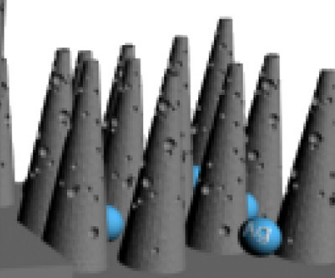

(d)
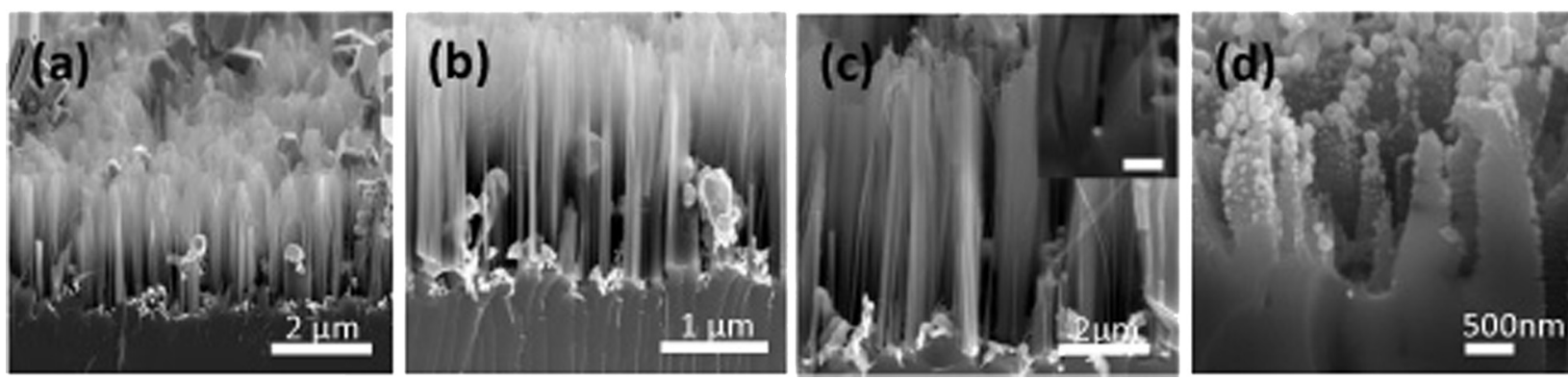

FIG. 2. (a-i)-(d-i) The schematic illustration of the proposed qualitative etching model for the formation of PSiNWs using Ag-assisted $\mathrm{HF} / \mathrm{H}_{2} \mathrm{O}_{2}$ electroless etching technique. (a-ii)-(d-ii) the corresponding SEM micrographs, prepared using various HF concentrations. 
It is noted that mesopores are mostly found near the top of the nanowires with an average pore size between 10 and $40 \mathrm{~nm}$. AgNPs were detected at the bottom section of the nanowires by EDS analysis in STEM mode. Based on the SEM and TEM analysis, the following qualitative model for the formation of PSiNWs is proposed. In $\mathrm{HF} / \mathrm{H}_{2} \mathrm{O}_{2}$ solution, part of the $\mathrm{Ag}$ is oxidized into $\mathrm{Ag}^{+}$by $\mathrm{H}_{2} \mathrm{O}_{2}{ }^{33}$ The $\mathrm{Ag}^{+}$catalyzes the dissolution of $\mathrm{Si}$ through the formation of $\mathrm{SiF}_{6}{ }^{2-}$. It is apparent that the transport of $\mathrm{Ag}^{+}$is isotropic while the AgNPs merely drop downwards. Hence, the AgNPs facilitated the nanowire formation through vertical chemical etching, while the isotropic diffusion of $\mathrm{Ag}^{+}$promoted lateral chemical etching and pore formation as illustrated in Fig. 2(a-i and a-ii).

The $\mathrm{Ag}^{+}$may be chemically reduced by the n-type silicon nanowires ${ }^{34}$ forming $\mathrm{Ag}$ particle that redeposited onto the sidewalls forming new $\mathrm{Ag}$ nucleation sites, and therefore the new localized lateral etching pathway. Furthermore, the nucleation of the AgNPs on the side-walls would also reduce the $\mathrm{Ag}^{+}$concentration locally, and accelerates the $\mathrm{Ag}^{+}$diffusion in the lateral direction. The laterally diffused $\mathrm{Ag}^{+}$will continue to catalyze the chemical etching of the sidewalls of $\mathrm{Si}$. Since the upper Si nanowires are exposed longer to the solutions, larger Si volume dissolves at the top (and creating more mesopores) than the bottom of the nanowires (Figs. 2(b-i and b-ii) and 2(c-i and c-ii)), consistent with the TEM image shown in Fig. 1(e). Furthermore, increasing the HF concentration accelerates the process described in our qualitative model; with the $\mathrm{Ag} \leftrightarrow \mathrm{Ag}^{+}+e^{-}$reversible reaction continues to penetrate the nanowires laterally to catalyze the $\mathrm{HF} / \mathrm{H}_{2} \mathrm{O}_{2}$ chemical reaction forming mesopores. Eventually, the mesopores merged leading to a reduction in length and pore-density, with the formation of conical PSiNWs in Fig. 2(d-i and d-ii).

Optical properties of the PSiNWs samples have been investigated using PL spectroscopy. It is known that the mesoporous silicon nanostructure, gives rise to strong visible emission. ${ }^{35}$ Figure 3(a) shows the PL spectra of the samples etched with $\mathrm{HF}$ concentrations of $1.8,2.8,4.8$, and $5.8 \mathrm{M}$ with a constant $\mathrm{H}_{2} \mathrm{O}_{2}$ concentration of $0.5 \mathrm{M}$. It is observed that the asymmetric PL spectra have two dominant peaks around 700 and $760 \mathrm{~nm}$. The sample etched with $4.8 \mathrm{M} \mathrm{HF}$ concentration has an additional hump at $670 \mathrm{~nm}$. The highest PL peak at $760 \mathrm{~nm}$ is related to the emission from $\mathrm{Si}-\mathrm{O}$ bond. ${ }^{35,36}$

In our case, we observe in Fig. 3(a) that the increase in integrated intensities of the broadband PL emissions correlates well with the increase in pore densities for samples etched using 1.8-4.8 M HF concentrations. With a HF concentration of $5.8 \mathrm{M}$, a reduction in PL integrated intensity is again consistent with a reduction in the pore-density of PSiNW.

After $\mathrm{HNO}_{3}$ and $\mathrm{HF}$ treatments for $5 \mathrm{~min}$ to remove the oxide, all samples show similar PL peak wavelength at $800 \mathrm{~nm}$ (inset of Fig 3(b)). However, without samples with HF treatment show a significant blue-shift with PL wavelength peak at $700 \mathrm{~nm}$ (Fig. 3(a)). This blue-shift and increase of PL intensity have been attributed to the presence of defect states in $\mathrm{Si}_{-} \mathrm{O}_{\mathrm{x}}$ that has been confirmed by XPS.
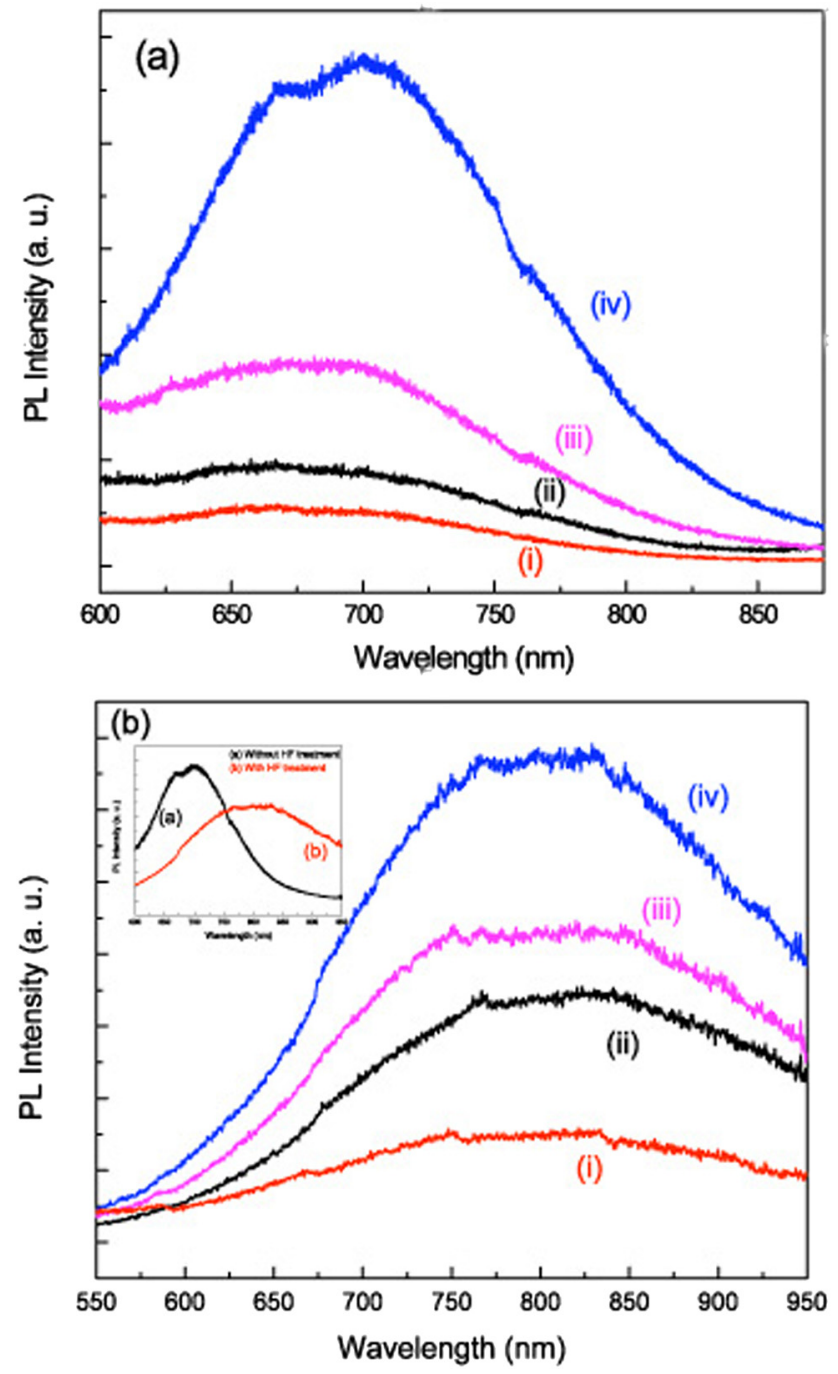

FIG. 3. PL spectra of PSiNWs as a function of HF concentration etched for $45 \mathrm{~min}$ (a): (i) $1.8 \mathrm{M}$, (ii) $2.8 \mathrm{M}$, (iii) $4.8 \mathrm{M}$, and (iv) $5.8 \mathrm{M}$. (b) after $\mathrm{HNO}_{3}$ treatment followed by $\mathrm{HF}(5 \%)$.

This has been correlated to the red shift of PL spectrum that suggests the interfacial between $\mathrm{Si}$ and surface oxide, as well as the quantum confinement effect, plays a critical role in the light emission process (i.e., the presence of nanocrystallites with size $<5 \mathrm{~nm}$ has been confirmed by HRTEM).

Several mechanisms have been proposed to explain the origin of strong PL emission for the indirect bandgap silicon material. These include: (i) the quantum confinement effects of free excitons within the Si-nanocrystallites, and (ii) $\mathrm{SiO}_{\mathrm{x}} /$ $\mathrm{Si}$ interface defects and/or defect states in the surface oxide, related to Si-O bond discussed in Sec. I..$^{23,35,37,38}$ Comparing the PL spectra before and after HF treatment, we believe that existence of oxide plays a significant role in changing the emission property of the nanowires.

The quantum confinement effect dictates that the characteristic size of the Si-nanocrystallites should be less than the Bohr radius of the free exciton of bulk $\mathrm{Si}$, which is around $5 \mathrm{~nm} .{ }^{39}$ From the TEM analysis, Si-nanocrystallites of $<5 \mathrm{~nm}$ has been observed (Fig. 4(a)). The inset of Fig. 4(a) shows the calculated fast-Fourier transform (FFT) of PSiNWs prepared using $4.8 \mathrm{M}$ HF concentration. The FFT revealed the spatial frequencies corresponding to $\{111\}$, 

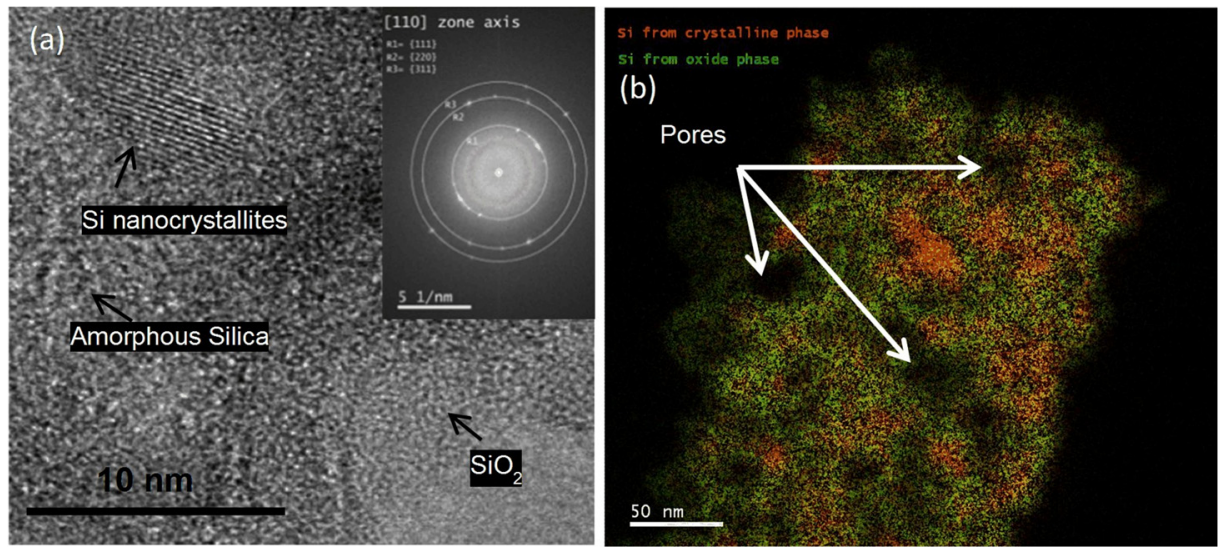

FIG. 4. (a) HRTEM and (b) EFTEM analysis of the top section of a PSiNW etched using $4.8 \mathrm{M}$ concentration of HF.

$\{220\}$, and $\{311\}$ d-spacing of Si crystal structure. The presence of these d-spacing implies that the PSiNW was oriented along the $\langle 110\rangle$ direction. This was expected as the (001) Si wafer was used to fabricate the NWs and etching was vertical with respect to the substrate surface. Also, the energy filtered TEM analysis of the top region of the PSiNW, shown in Fig. 4(b), confirms the existence of Si nanocrystallites and silica amorphous structures indicating the possible strong PL emission from the highly quantum-confined Si nanocrytallite structures. This prediction correlates positivity with our previous discussion on the effect of pore-density on PL enhancement. The above argument further confirm our observation that samples etched with HF concentration of 5.8 M (i.e., with low pore and Si-nanocrystallites densities) results in a decrease in PL intensity. The evolution of PL peak intensity with HF concentration is hence consistent with the physical changes in the PSiNWs developed in our etching model.

The XPS measurements have been conducted to study the role of $\mathrm{SiO}_{\mathrm{X}} / \mathrm{Si}$ interface defects and/or defect states in surface oxide to the broadband PL emissions in PSiNWs. Figure 5 exhibits the Si 2p core-level spectra having two peaks around

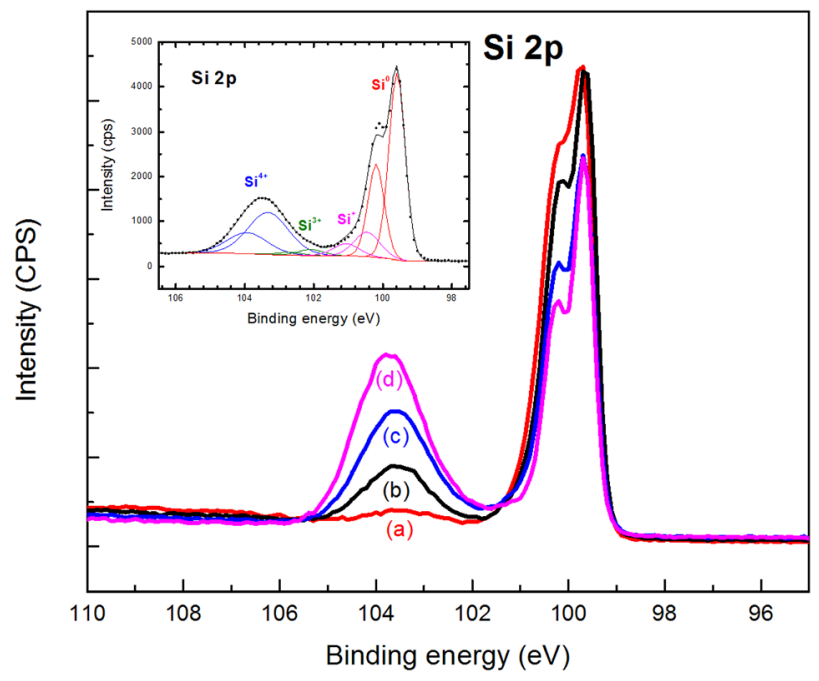

FIG. 5. XPS spectra of PSiNWs as a function of HF concentration etched for $45 \mathrm{~min}$ : (a) $1.8 \mathrm{M}$, (b) $2.8 \mathrm{M}$, (c) $4.8 \mathrm{M}$, and (d) $5.8 \mathrm{M}$. Inset: the XPS spectra showing the 5 sets of doublet-fitted signatures of $\mathrm{Si}^{0}(\mathrm{Si}), \mathrm{Si}^{4+}$ $\left(\mathrm{SiO}_{2}\right), \mathrm{Si}^{1+}\left(\mathrm{Si}_{2} \mathrm{O}\right), \mathrm{Si}^{2+}(\mathrm{SiO})$, and $\mathrm{Si}^{3+}\left(\mathrm{Si}_{2} \mathrm{O}_{3}\right)$ for the PSiNWs sample etched using $4.8 \mathrm{M}$ concentration of $\mathrm{HF}$ for $45 \mathrm{~min}$.
$100.0 \mathrm{eV}$ and $103.5 \mathrm{eV}$, which correspond to the silicon and silicon dioxide peaks. The lower binding energies near $100.0 \mathrm{eV}$, i.e., the Si $2 \mathrm{p}_{3 / 2}(99.7 \mathrm{eV})$ and Si $2 \mathrm{p}_{1 / 2}(100.1 \mathrm{eV})^{40}$ spin-orbit splitting are well resolved. The inset of Fig. 5 shows the XPS spectra of the PSiNW etched using $4.8 \mathrm{M}$ concentration of HF. The XPS spectra was fitted using 1 doublet (Si $2 \mathrm{p}_{3 / 2}-\mathrm{Si} 2 \mathrm{p}_{1 / 2}$ ) (with a fixed area ratio equal to 2:1 and doublet separation of $0.6 \mathrm{eV}$ ) for each of the 5 XPS signatures for $\mathrm{Si}^{0}(\mathrm{Si}), \mathrm{Si}^{4+}\left(\mathrm{SiO}_{2}\right), \mathrm{Si}^{1+}\left(\mathrm{Si}_{2} \mathrm{O}\right), \mathrm{Si}^{2+}(\mathrm{SiO})$, and $\mathrm{Si}^{3+}\left(\mathrm{Si}_{2} \mathrm{O}_{3}\right),{ }^{41-44}$ indicating the absence of $+2 \mathrm{Si}$ oxidation state. The $\mathrm{SiO}_{2}$ peak was relatively broad compared to the $\mathrm{Si}$ peak due to phonon broadening. ${ }^{45}$ Also, as HF concentration increases, the $\mathrm{SiO}_{2}$ peak increases while the $\mathrm{Si}$ peak intensity decreases (Figs. 5(a)-5(d)).

This is expected based on our qualitative etching model, where $\mathrm{Ag}^{+}$penetrates the nanowire to oxidize and dissolve $\mathrm{Si}$ materials forming mesopores, and tapered nanowires. The formation of mesopores further increases the surface to volume ratio of the nanowires, thereby accelerating the $\mathrm{Si}$ oxidation and dissolution rates. However, $\mathrm{SiO}_{2}$ alone should not give rise to the PL emission. Rather, defect states would contribute to $\mathrm{PL}$ emission. Indeed, we observed $\mathrm{Si}^{1+}\left(\mathrm{Si}_{2} \mathrm{O}\right)$ and $\mathrm{Si}^{3+}\left(\mathrm{Si}_{2} \mathrm{O}_{3}\right)$ XPS signatures in the inset of Fig. 5, which may originate from dangling bonds and volumetric stress that distorted the PSiNWs forming localized defect states. Therefore, the emissions from surface/defect states in oxide may contribute to the red PL emission, in agreement with the results obtained in Refs. 23 and 46, in addition to the contribution from quantum confinement effect.

\section{CONCLUSIONS}

In summary, we have developed a qualitative etching model elucidating the conical PSiNWs formation using $\mathrm{Ag}$ assisted $\mathrm{HF} / \mathrm{H}_{2} \mathrm{O}_{2}$ electroless etching method and n-type $\mathrm{Si}$ substrates. We identified the primary etching pathway in a vertical and downward direction as a result of Ag particle catalysis along the (001) crystal orientation, and the secondary etching pathway in the lateral directions owing to the $\mathrm{Ag} \leftrightarrow$ $\mathrm{Ag}^{+}+e^{-}$reversible reaction catalyzing the mesopores formation. The PL, TEM analysis, and XPS results showed evidence of the quantum confinement effect and oxide dangling bond/defect states in surface oxide, respectively, in contributing to the broadband PL emissions in our samples. The 
combination of the physical properties of SiNWs and mesopores can be potentially useful in optical sensors applications, and as anti-reflection layer for silicon-based solar cells.

${ }^{1}$ X. Y. Zhao, C. M. Wei, L. Yang, and M. Y. Chou, Phys. Rev. Lett. 92, 236805 (2004).

${ }^{2}$ Y. Cui and C. M. Lieber, Science 291, 851(2001).

${ }^{3}$ C. M. Lieber and Z. L. Wang, MRS Bull. 32, 99 (2007).

${ }^{4}$ A. Najar, J. Charrier, H. Ajlani, N. Lorrain, S. Haesaert, M. Oueslati, and L. Haji, Mater. Sci. Eng., 146B, 260 (2008).

${ }^{5}$ A. Najar, N. Lorrain, H. Ajlani, J. Charrier, M. Oueslati, and L. Haji, Appl. Surf. Sci. 256, 581(2009).

${ }^{6}$ A. Najar, H. Ajlani, J. Charrier, N. Lorrain, S. Haesaert, M. Oueslati, and L. Haji, Physica B 396, 145 (2007).

${ }^{7}$ H. Koyama, T. Nakagawa, T. Ozaki, and N. Koshida, Appl. Phys. Lett. 65, 1656 (1994).

${ }^{8}$ L. T. Canham, M. R. Houlton, W. Y. Leong, C. Pickering, and J. M. Keen, J. Appl. Phys. 70, 422 (1991).

${ }^{9}$ Y. Huang, X. Duan, and C. M. Lieber, Small 1, 142 (2005).

${ }^{10}$ M. T. Bohr, IEEE Trans. Nanotechnol. 1, 56 (2002).

${ }^{11}$ C. M. Lieber, Solid State Commun. 107, 607 (1998).

${ }^{12}$ Y. N. Xia, P. D. Yang, Y. G. Sun, Y. Wu, N. Mayers, B. Gates, Y. Yin, F. Kim, and H. Yan, Adv. Mater. 15, 353 (2003).

${ }^{13}$ R. S. Wagner and W. C. Ellis, Appl. Phys. Lett. 4, 89 (1964).

${ }^{14}$ A. M. Morales and C. M. Lieber, Science 279, 208 (1998).

${ }^{15}$ Y. F. Zhang, Y. H. Tang, N. Wang, D. P. Yu, C. S. Lee, I. Bello, and S. T. Lee, Appl. Phys. Lett. 72, 1835 (1998).

${ }^{16}$ L. Schubert, P. Werner, N. D. Zakharov, G. Gerth, F. M. Kolb, L. Long, U. Gösele, and T. Y. Tan, Appl. Phys. Lett. 84, 4968 (2004).

${ }^{17}$ T. Stelzner, M. Pietsch, G. Andrä, F. Falk, E. Ose, and S. Christiansen, Nanotechnology 19, 295203 (2008)

${ }^{18}$ M. Lu, M. K. Li, L. B. Kong, X. Y. Guo, and H. L. Li, Chem. Phys. Lett. 374, 542 (2003).

${ }^{19}$ F. C. K. Au, K. W. Wong, Y. H. Tang, Y. F. Zhang, I. Bello, and S. T. Lee, Appl. Phys. Lett. 75, 1700 (1999)

${ }^{20}$ D. P. Yu, C. S. Lee, I. Bello, X. S. Sun, Y. H. Tang, G. W. Zhou, Z. G. Bai, Z. Zhang, and S. Q. Feng, Solid State Commun. 105, 403 (1997).

${ }^{21}$ N. Wang, Y. H. Tang, Y. F. Zhang, C. S. Lee, I. Bello, and S. T. Lee, Chem. Phys. Lett. 299, 237 (1999).

${ }^{22}$ R. Juhasz, K. Kylmänen, A. Galeckas, and J. Linnros, Mater. Sci. Eng., C 25, 733 (2005).

${ }^{23}$ A. I. Hochbaum, D. Gargas, Y. J. Hwang, and P. Yang, Nano Lett. 9, 3550 (2009).
${ }^{24}$ D. Kumar, S. K. Srivastava, P. K. Singh, K. N. Sood, V. N. Singh, N. Dilawar, and M. Husain, J. Nanopart. Res. 12, 2267 (2010).

${ }^{25}$ S. K. Srivastava, D. Kumar, P. K. Singh, M. Kar, V. Kumar, and M. Husain, Sol. Energy Mater. Sol. Cells 94, 1506 (2010).

${ }^{26}$ K. Q. Peng, Y. J. Yan, S. P. Gao, and J. Zhu, Adv. Mater. 14, 1164 (2002).

${ }^{27}$ T. Qiu, X. L. Wu, Y. F. Mei, G. J. Wan, P. K. Chu, and G. G. Siu, J. Cryst. Growth 277, 143 (2005).

${ }^{28}$ X. Zhong, Y. Qu, Y. C. Lin, L. Liao, and X. Duan, ACS Appl. Mater. Interfaces 3, 261-270 (2011).

${ }^{29}$ Y. Mori, M. Tanemura, and S. Tanemura, Appl. Surf. Sci. 228, 292 (2004).

${ }^{30}$ B. J. Tielsch, J. E. Fulghum, and D. J. Surman, Surf. Interface Anal. 24, 459 (1996).

${ }^{31}$ E. S. Kooij, K. Butter, and J. J. Kelly, Electrochem. Solid State Lett. 2, 178 (1999).

${ }^{32}$ D. R. Turner, J. Electrochem. Soc. 107, 810 (1960).

${ }^{33}$ Y. Qu, H. Zhou, and X. Duan, Nanoscale 3, 4060 (2011).

${ }^{34}$ M. L. Zhang, K. P. Peng, X. Fan, J. S. Jie, R. Q. Zhang, S. T. Lee, and N. B. Wong, J. Phys. Chem. C 112, 4444 (2008).

${ }^{35}$ A. G. Cullis, L. T. Canham, and P. D. J. Calcott, J. Appl. Phys. 82, 909 (1997).

${ }^{36}$ L. Lin, S. Guo, X. Sun, J. Feng, and Y. Wang, Nano. Res. Lett. 5, 1822 (2010).

${ }^{37}$ A. J. Kontkiewicz, A. M. Kontkiewicz, J. Siejka, S. Sen, G. Nowak, A. M. Hoff, P. Sakthivel, K. Ahmed, P. Mukherjee, S. Witanachchi, and J. Lagowski, Appl. Phys. Lett. 65, 1436 (1994).

${ }^{38}$ Y. Zhao, D. Yang, W. Sang, D. Li, and M. Jiang, Mater. Sci. Eng., B 116, 95 (2005).

${ }^{39}$ Z. G. Bai, D. P. Yu, J. J. Wang, Y. H. Zou, W. Qian, J. S. Fu, S. Q. Feng, J. Xu, and L. P. You, Mater. Sci. Eng., B 72, 117 (2000).

${ }^{40}$ M. F. Beaux, I. I. N. J. Bridges, M. DeHart, T. F. Bitterwolf, and D. N. McIlroy, Appl. Surf. Sci. 257, 5766 (2011).

${ }^{41}$ F. J. Himpsel, B. S. Meyerson, F. R. McFeely, J. F. Morar, A. Taleb-Ibrahimi, and J. A. Yarmoff, in Photoemission and Absorption Spectroscopy of Solids and Interfaces with Synchrotron Radiation, edited by M. Campagna and R. Rosei (North-Holland, Amsterdam, 1990), p. 203.

${ }^{42}$ E. G. Barbagiovanni, L. V. Goncharova, and P. J. Simpson, Phys. Rev. B 83, 035112 (2011).

${ }^{43}$ M. L. Green, E. P. Gusev, R. Degraeve, and E. L. Garfunkel, J. Appl. Phys. 90, 2057 (2001).

${ }^{44}$ O. Renault, R. Marlier, M. Gely, B. D. Salvo, T. Baron, M. Hansson, and N. T. Barrett, Appl. Phys. Lett. 87, 163119 (2005).

${ }^{45}$ G. Hollinger and F. J. Himpsel, Appl. Phys. Lett. 44, 93 (1984).

${ }^{46}$ L. H. Lin, X. Z. Sun, R. Tao, Z. C. Li, J. Y. Feng, and Z. J. Zhang, J. Appl. Phys. 110, 073109 (2011). 